\title{
11
}

\section{Creating Engaged Departments: A Program for Organizational and Faculty Development}

\author{
Kevin J. Kecskes, Sherril B. Gelmon, Amy Spring \\ Portland State University
}

Portland State University encourages faculty participation in service-learning by providing faculty with individual incentives to support and reward them. Now, in recognition of this central role of the department in higher education, administrators interested in creating sustained civic engagement initiatives on campus are looking to the department as a strategic leverage point for change. This chapter investigates a yearlong engaged department initiative and finds that a collective approach can (re)connect individual faculty to their initial motivations for engaging in the profession, to a community of scholars, to their students, and also to their surrounding community.

\section{Introduction}

Higher education faculty members find their intellectual and professional home in their discipline. At the institutional level, the disciplines are organized as departments or similar academic units. Departments house faculty with similar scholarly interests, where the chair and other leaders set policies in accord with disciplinary expectations, and faculty generally support and review each other's work as well as look to each other for collaboration and collegiality. These administrative units of discipline-related faculty provide a structure to recruit and select new faculty, negotiate research agendas, develop reward systems, establish curriculum, and respond to disciplinary and student priorities (Leaming, 1998). In recognition of this centrality of the 
department, administrators interested in effecting lasting change on campus are looking to the department as a strategic leverage point for change.

Portland State University (PSU) encourages faculty participation in service-learning in part by providing faculty with individual incentives to support and reward them. One of the incentives, administered by PSU's Center for Academic Excellence (CAE), has been a competitive, peer reviewed, servicelearning, small grant program. Since 1997, more than 200 faculty have received these grants for service-learning course development or enhancement. This individual-level strategy has significantly facilitated the expansion of service-learning at PSU. However, faculty have reported frustration with the lack of department resources to support their service-learning and civic engagement work. They have also expressed concern that the existing practice of providing grants to support individuals required them to be in direct competition with their department colleagues. Shifting to a department incentive strategy would encourage individual faculty within department units to work together and provide funds to help support the development of a sustainable department infrastructure for ongoing engagement.

\section{The Engaged Department Concept}

There have been many discussions about engaged universities, departments, and disciplines at various national meetings and in multiple publications. Initiatives related to service-learning and civic engagement were initially perceived as institutional activities, with considerable support from senior administration. As campuses gained increased experience in civic engagement, the faculty value of conceptual, disciplinary frameworks was acknowledged, and new initiatives began within the disciplines (e.g., the Campus Compact Engaged Disciplines Project) to provide faculty with peer review and recognition. This led to further consideration of the department (i.e., a cluster of disciplinary related individuals who work together and are rewarded through this unit) as a key unit for institutional transformation.

Since 2000, Campus Compact has taken the lead in department engagement by offering the Institute on the Engaged Department. The institute helps academic departments think about the department as a unit of engagement and change (see the Campus Compact web site for more information on the institute: http://www.compact.org/faculty/engageddept.html). PSU has participated in this initiative by forming department teams consisting of faculty, the chair, and a community partner, who work together for three intense days to develop action strategies for engagement within the department context. 
These institutes have proven to be a valuable tool for launching department plans (Battistoni, Gelmon, Saltmarsh, Wergin, \& Zlotkowski, 2003).

This national effort to encourage increased and enhanced communityuniversity partnerships by focusing resources on academic departments provided the impetus for the CAE staff to rethink our individual faculty incentive strategy. In 2001, we decided to build upon the experiences of Campus Compact to develop and pilot a similar campus-wide program, the Engaged Department Initiative. In our initiative, we use department as a general term for a variety of academic units that have equivalent functions to a department. For example, one unit was a major component of an academic program, and two other units are called schools but function as departments.

Our program was designed to involve a select number of departments in a yearlong planning and development process to create action strategies relevant to their context with respect to engagement. Each department would receive various resources (human, fiscal, printed, and consultative) to assist in this work. The aim was for faculty and departments to become more engaged in mission-related activities relevant to civic engagement and related teaching and research strategies.

\section{Research Questions}

We wanted to develop evidence to answer the following questions:

- What can departments accomplish through a one-year program with respect to developing civic engagement activities?

- What opportunities exist to support departments in this work, and how can they take advantage of them?

- What challenges exist, and how might they be overcome?

- What central institutional capacity is needed to help departments become engaged departments?

Our intent was to learn as much as we could through this initial one-year project in order to inform future development activities sponsored by the university and to provide a basis for dissemination to a larger audience. Given the interest in department engagement at many institutions in the United States and our impression that during the 2001-2002 academic year no other campus had pursued a similar formal program to build institutional capacity around department engagement, we believed there was much to learn that would have local relevance and broad applicability. 


\section{Methods}

Portland State University has invited participation in various developmental programs sponsored by CAE through a request-for-proposal (RFP) process. An RFP is created and mailed in hardcopy and electronic formats to all faculty and academic leaders in the university. We determined that an RFP process was appropriate for the Engaged Department Initiative in order to make the invitation open to all departments on campus. We identified departments we believed already had an interest in this area, and we gave them additional encouragement to consider the RFP and determine whether they could assemble a team to apply for participation. The RFP invited departments (programs, units, etc.) to "participate in an in-depth process to become an engaged department." Given that this work was funded in part by a grant from the Corporation for National and Community Service, we defined an engaged department in keeping with the corporation's goals as one that does the following:

- Uses community-based (or service) learning to help students integrate community work and reflection into their academic studies

- Encourages the scholarship of engagement where community-based action research is pursued that addresses issues defined by community participants

- Provides support to other activities prominent on the department agen$\mathrm{da}$ in which the department responds to the community through the activities that fulfill the university's mission

One of our strategies for inviting departments to apply to participate in this project was to offer department grants to support their work. The RFP specified options regarding the use of the grants, with an emphasis on grants that would accomplish one or more of the following: purposefully integrate community-based work into teaching and scholarship; develop communitybased learning as a regular part of the academic content and expectations of a curriculum; and/or develop and implement plans for department coherence for engagement in scholarly and service activities. The RFP included guidelines regarding the use of funds, and it specified expectations of participating departments to include designation of a three- to five-person leadership team, a commitment to participate in an internal planning and development process, and a commitment to participate in monthly cross-campus discussions of initiative participants to build collective knowledge and learning. 
Proposals were reviewed by a team assembled by the Center for Academic Excellence, who independently ranked each proposal against nine primary criteria derived from the RFP content and three other criteria related to institutional goals (in order to gain leverage across campus initiatives). Reviewers met, discussed their rankings, and identified seven departments to invite to participate: Department of English, Department of Mathematical Sciences, Department of Psychology, School of Business (management grouping), School of Community Health, School of Urban Studies and Planning (community development grouping), and University Studies (freshman inquiry grouping). Each team identified at least three faculty participants, and some teams included a graduate student. Although teams were also invited to include a community partner on their team, none elected to do so.

\section{Program Process and Content}

Upon acceptance of participation in the Engaged Department Initiative, each team was sent a planning document to complete. We modified the planning document used by Campus Compact for the national institute (Campus Compact, 2001). This document asked departments to reflect on the question "Where are you now?" They did this by:

- Articulating mission

- Describing strengths, weaknesses, challenges, and opportunities

- Offering their own definition of civic engagement

- Assessing the extent of engagement within the department

- Identifying core communities and constituencies

Departments then addressed the question "Where do you want to be?" This led to articulating goals for the project, projecting accomplishments, and anticipating impact(s) of the project. These documents provided a useful basis for helping departments begin their work and for assisting program leaders in gaining a better understanding of the assets and challenges of the participating departments.

There were three major components of the work of this project: individual department activities, facilitated learning/networking sessions of the seven departments and program leaders, and individual monthly consultations with each department. The common theme for all participating departments was the opportunity to learn together through the monthly sessions 
and to identify challenges and possible solutions. Of the seven sessions that were held, six were content based and addressed topics that included strategizing barriers and facilitators, curricular change, engaging the rest of the department, and related scholarship. The final session was a public poster session at which each department presented a poster summarizing its work. The campus community and others interested in civic engagement were invited to view the posters and discuss the content and experiences with the department representatives.

Our assessment of this project is based on six primary sources of evidence: the initial project proposals, the planning documents submitted at the beginning of the process, observations throughout the monthly learning sessions, observations from the monthly consultations, final project reports (including posters), and a final interview conducted by the CAE staff with each team. We conducted content analyses of each of the documents and collectively analyzed our individual and group reflections and observations.

\section{Findings}

Findings are based on a review of the various sources of evidence. We have synthesized these according to the four research questions that address accomplishments, opportunities and facilitators of department engagement, challenges and strategies, and necessary central institutional capacity.

\section{Accomplishments}

What can departments accomplish through a program lasting one academic year with respect to developing civic engagement activities? The seven departments proposed projects that varied tremendously. Notwithstanding these differences, similarities do appear among them. In terms of accomplishments, we have organized the projects into three broad categories: creating initial course offerings, fostering broad-scale engagement, and refining engagement activities. In all cases it should be noted that the project period of this initial study was approximately seven months. This abbreviated time period affected the scope and depth of what the departments were able to accomplish.

Creating initial course offerings. Two departments focused their efforts on developing and offering a service-learning course as a strategy to build civic engagement within their units. Both departments strategically determined the critical place within the curriculum where a service-learning course would best serve student learning and recognized that students within their 
academic programs could benefit from discipline-related service-learning courses. Each department had limited previous experience offering servicelearning courses; therefore, the focus for these two teams was to develop discipline-based service-learning expertise among a small group of department faculty. By offering these initial service-learning courses, the departments were able to develop their comfort and skills with service-learning pedagogies, confirm the need for discipline-based service-learning (as expressed by their students), and explore ways to expand their efforts to include additional service-learning courses in subsequent academic terms. The two departments were also able to assess the impact their service-learning courses had on student learning, particularly as it relates to the students' understanding of themselves in discipline-based professional settings. Now both departments are exploring ways to make the service-learning experiences a sustained part of their curricula.

Fostering broad-scale engagement. Three departments proposed projects to expand and enhance the level of engagement the departments' faculty and students have with the surrounding community. Two of the three departments proposed a department-focused faculty discussion series to increase understanding of how and why to integrate service-learning into course curricula. The third department proposed a project centered on a communityidentified concern. The focus of this department's work was to create department enthusiasm to integrate this community-identified concern into a department-wide teaching and research agenda.

These three departments hosted a series of events designed to encourage department-wide discussions about integrating community-based projects into teaching and research. Some of these events were held during regularly scheduled department meetings. Others were brown-bag meetings meant to provide faculty with specific service-learning skills. Still others were studentorganized department events meant to highlight and encourage participation in a specific community-identified concern. Finally, some were events where nationally recognized speakers were invited to discuss their communitybased work. Although these events took many different forms, the overall goal for these units was to encourage department-wide discussions about why and how to engage with the Portland metropolitan community.

As a result of these events, the three departments that employed this department-wide change strategy have been able to document an increased interest among their faculty colleagues to integrate community-based engagement into their teaching and research. In each department, four new servicelearning courses will be offered during the next academic year. Additionally, an increased number of internships for graduate students were created, a new 
web site that identifies community projects now proclaims success, and at least three community-based research publications are in press. In the ideal state, community-building efforts can (re)invigorate deep interest in and (re)connect individual faculty members to their initial motivations for engaging in the profession, to a community of scholars, to their students, and to their surrounding community.

Refining engagement activities. Although all of the departments involved assessed their engagement activities, two departments used this initiative to more comprehensively assess the current level and quality of the engagement activities taking place across their departments. Both have a long tradition of community engagement, and they saw this initiative as a means to more fully understand what they were currently doing and to inform their practice to enhance department work with their community partners.

They used different processes to assess their current engagement activities. One department took a highly formal approach which included using facilitated focus groups with students and a survey of students, faculty, and community partners. This data was used to determine their current level of engagement and strategies that would enhance community-department partnerships. The other department utilized a broad-scale engagement approach. A graduate student interviewed each of the faculty members within the department to determine the extent and nature of existing community-based teaching and research. This approach allowed the graduate student to gain a deep and highly specific understanding of the types of projects faculty were pursuing with the community and a good sense of the resources they need to enhance their work with the community.

As a result of these efforts, the two departments are now able to articulate with increased clarity the level at which their departments are engaged in community-based teaching and research. Also, they are able to structure department resources to strengthen their engagement efforts. In the next academic year, both departments will put structures in place to enhance the quality of community-based engagement for their students, faculty, and community partners.

\section{Opportunities and Facilitalors of Department Engagement}

Moving from a model of support of individual faculty to a model where support is provided to groups of faculty within a department substantially changes the way in which community-based teaching and research is understood and advanced within the university. The facilitators for increasing and enhancing community-based work when departments are the strategic point 
for resource allocation are significantly different. The department is the community in a sense. Using the department as the unit of focus models local community development. Motivation for community engagement does not come primarily from a centralized service-learning center. Instead, it emanates from the department team members involved in the project. There are several facilitating elements that assisted the seven engaged department teams in their work.

Opportunities for faculty to work together. Establishing programmatic structures to facilitate teams of faculty to work together was one of the initial motivators to shift from a program model that encourages individual faculty to integrate community engagement into their teaching and research to one that encourages department teams to integrate engagement into the collective work of the department. The faculty teams involved in this initiative found that the support facilitated the development of useful and important actions that would not have occurred if they had not been encouraged to work as a team. One team utilized the initiative as a means to educate colleagues about the theoretical and scholarly foundations of community engagement. They had a modest goal to encourage their colleagues to integrate community engagement into their own work but, more importantly, they sought to provide information so that those colleagues would be more effective at evaluating promotion and tenure portfolios that have documented community engagement activities.

Several of the teams described their work together as offering critical opportunities to think about their departments' complete curriculum and how community engagement can be woven throughout with developmentally appropriate projects that would match students' theoretical understanding and skills. The department teams were made up of individual faculty, some with many years of community-based project experience and some with relatively little previous experience. The teams provided an infrastructure to have faculty with more experience mentor and assist those with less experience. Faculty from each team reported they were able to accomplish much more because of the synergy created through their work together on this project. Without the luxury of being able to provide funding and programmatic support to promote this collective work among faculty, the level of attention and focus dedicated to department engagement would have been minimal.

Discipline-focused resources. Development of discipline-specific resources to assist faculty and students in their community-based engagement was an important facilitator of the departments' work. The Engaged Department Initiative was created in part to respond to faculty requests for assistance with the development of department infrastructure to support community 
engagement. Most of the departments used a portion of their funds to develop a discipline-specific library of electronic and material items that would assist them in effective community-based teaching and research. Department teams collected sample syllabi, course assignments, examples of structured reflection strategies, publication and presentation outlets for communitybased research and scholarship, and student learning assessment techniques, as well as lists of community partners with whom the department could effectively work. Once assembled, the department teams made these materials accessible to the entire department by creating an electronic link to the departments' web pages, locating the materials in the departments' libraries, or developing copies of the materials and distributing them to each department faculty member. Many of these items already exist in the campus faculty development center, but having access to them at the department level and having them specifically tailored to the discipline helped faculty and students in their engagement initiatives.

In addition to these print and electronic resources, most of the teams utilized a portion of their funds to hire a student to assist them with their engagement projects. The students were identified and selected by the department teams, and in almost every case, the students were majors from the department with whom they were working. Faculty teams uniformly recognized that student involvement with this initiative was an essential facilitator of the project. Students attended to many of the logistical elements that moved the projects through their various implementation stages, such as organizing guest speakers for department workshops, identifying community partners with whom faculty and students could work, organizing department library resources, helping service-learning students get to their service sites, and helping to organize various elements of assessment. In addition to these varied and essential logistical support roles, the students provided the faculty teams with a student voice and perspective. Those departments that did not utilize students as facilitators of their department engagement projects reported that they would incorporate students as a resource to advance their work if they were to propose a project of this type again.

We have identified two primary reasons why these student, electronic, and material resources served as important facilitators to the work of the departments: most of the resources were identified by the department teams involved in the initiative, and most of the resources were specifically tailored to the teams' disciplines. Both of these factors contribute to the usability of the resources. They were selected and organized by the people who will access them and were based on a theoretical framework familiar to the departments. 
Individual and organizational commitment. Organizational and individual leadership on behalf of community engagement facilitated the effectiveness of the Engaged Department Initiative. For those departments in which civic engagement and applied learning experiences reflected a long tradition and articulation in the department mission, the ability to mobilize department resources to increase and enhance engagement within the department came with relative ease. Teams cited their department mission and academic tradition as recognition that engagement in the community is a viable and expected activity of the department. Many faculty accepted that communitybased teaching and research is a legitimate and expected means to contribute specifically to the department and generally to the disciplinary field.

For those teams where the department's chair expressed a high level of leadership and commitment to the Engaged Department Initiative, the efforts of the faculty team were tremendously enhanced. The chair's commitment helped the department team tie the initiative to other department initiatives. They were also able to garner additional resources to support the initiative, mobilize increased faculty support and participation across the department, and use department meetings to discuss the Engaged Department Initiative.

Those departments without such organizational and individual leadership were able to make advances with respect to department engagement; however, they did not engage the entire department in conversations about integration of engagement throughout the curriculum. These departments took initial steps by offering a limited number of service-learning courses and utilizing them to understand and promote how student learning is affected by the applied experiences service-learning offers. As faculty develop expertise with respect to service-learning pedagogies, the conversation and application of engagement strategies within the department is expected to increase. Faculty will likely expand their notion of engagement beyond service-learning and begin to explore expanded ways to incorporate engagement into the work of the department.

Broad understanding of community engagement. To the extent that the Engaged Department Initiative encouraged departments to think broadly about community engagement (including service-learning courses, internships, practica, field study, community-based scholarship, and action research), the level of department engagement and interest increased. Several teams proposed engagement projects that primarily focused on expanding and enhancing service-learning activities within the department. This singular goal allowed them to collect focused department resources and craft specific language that was inviting to their faculty colleagues concerning the 
development of service-learning in their disciplinary work. Although effective in facilitating the accomplishment of some targeted outcomes, the narrow focus of their engagement efforts limited the number of people within the department who thought of their work and interests in engagement terms. With a broader exploration and articulation of engagement, these departments would likely have been able to attract the interest of more department colleagues.

\section{Challenges and Strategies}

Department reports, faculty interviews, and observations have helped us to identify programmatic and institutional structural challenges, as well as conceptual challenges to supporting the development of engaged departments.

Predictably, perceived shortages of resources, specifically time and money, surfaced as recurring challenges to department teams. In particular, the short timeframe of the initiative was a clear source of concern. To partially mitigate this concern, the second year of the program ran the full academic year (September to June).

A second concern related to the size and scope of the grants. Total resources available to support this initiative are dependent primarily upon external grant support with limited internal allocations of funds. An approach to address minimal funds is to limit the number of department teams selected and provide each team with additional resources. While this may help the individual team(s), it limits the diffusion of the initiative across multiple departments. A second approach is to mandate that each department team provide matching funds toward the effort. This requirement could raise the total amount of resources available for the team and the profile of the initiative, potentially leveraging additional commitments from the department chair. An issue underlying this challenge is the perception that engagement requires new funds as compared to a reallocation of existing resources and effort. The feasibility of providing multiyear grant support to participating teams will depend on the availability of external funding.

Another challenge was the perceived utility of the monthly cross-department learning sessions. Most participants appreciated the opportunity to regularly discuss progress, voice concerns to an interdisciplinary cohort, and brainstorm potential solutions to specific department issues. However, these sessions lacked coherence as an integrated program due to the diversity of interests, needs, and availability of team members, which raised further challenges of developing common foundational knowledge across the participating teams. Team members provided many suggestions and insights regarding 
how to increase the value this programmatic component might add. The suggestions for enhancement ranged from stylistic to substantive, including frequency of meetings, balance of efforts to share individual experiences versus work on group learning on a new theme, requirements of attendance, provision of focused professional development seminars on key engagement topics (such as syllabus conceptualization, partnership development, facilitating reflection, planning strategies), and the most effective strategies for teaching and learning with an interdisciplinary faculty group.

A recurring challenge for many program participants was indifference or resistance of faculty. Some questions surfaced toward the end of the initiative, including:

- "Does everyone in my department need to be involved for us to be an engaged department? What percentage of involvement will make us engaged?"

- "To determine our overall level of department engagement, should we consider only our tenure-track faculty, or should we consider the views and activities of adjuncts associated with the department as well?"

Participants observed that community-based engagement activities were not necessarily suitable for all individuals. As well, most agreed that increasing the quality and quantity of department-level engagement activities was a worthy pursuit, independent of an arbitrary determination of critical mass. Many participants agreed that student and community member participation in department dialogue and decisions would, over time, help determine which departments were perceived as engaged. However, this position does not account for perceptions of the rest of the institution as a whole, other departments within the institution, or the field at large. Concerns about levels and determination of engagement appeared somewhat counterproductive.

A final challenge dealt with goal accomplishment. In the initial planning document, departments articulated their own specific goals based upon their knowledge of themselves, the institution, and their disciplines. Emphasis should be placed upon each team assessing their progress with respect to these individualized goals throughout the initiative rather than trying to compare performance to some artificial generalized norm. Teams should periodically revisit their goals, assess their interim progress, and reflect on how to accelerate their progress. 


\section{Necessary Central Institutional Capacity}

What central institutional capacity is needed to help departments become engaged departments? Four elements emerged from the work of the engaged department initiative.

Central support office. The presence of a central administrative office with dedicated staff charged with faculty development and support of service-learning is a key factor for increasing department engagement. Staff are available to secure and disseminate funding and provide grant program structure and technical assistance. The presence of a centralized office (especially one reporting to academic affairs) provides legitimacy to community-based, civically motivated professional faculty activities. The role and scope of the centralized office needs to be determined in alignment with the particular campus climate and culture.

At PSU, the provision of civic engagement opportunities is centralized generally, while the design and activity parameters, as well as the responsibility and ownership of the activities, are decentralized. The central office (CAE) provides overarching direction and associated funding and support for initiatives, while the actual programs grow out of department or individual faculty interests and commitments.

This structural arrangement makes sense for several reasons. The central office monitors trends and allocates resources to ensure that campus engagement activities align with the best practices in the field. Meanwhile, departments and individual faculty translate broad visions and trends into scholarly work that makes the most sense in the contexts of their disciplinary foci. This arrangement strategically leverages resources, providing opportunities for individuals most appropriately positioned on campus to maximize their efforts and avoid unnecessary duplication. Furthermore, the overarching view of CAE facilitates cross-institutional programming and communication. For example, in the case of the Engaged Department Initiative, a key program design parameter was the development of a cross-disciplinary learning collaborative which, in the best-case scenario, may evolve into a learning community. The center can generate economies of scale in terms of university-wide programmatic activities. In turn, this creates organizational capacity that is both operationally effective and externally attractive to funding agencies.

Leadership and commitment. Departments that were able to make substantial progress intentionally included the department chair in program activities. Ideally, the chair articulates a compelling department purpose and facilitates connections between core department activities and faculty agendas on one hand, and between the school and university core purposes on the other. Not unlike the presence of a respected centralized office, a strong and supportive chair legitimizes community-based, civically motivated scholarly 
activities. This manifests itself in myriad ways, including internal resource allocation, recognition of faculty activities, and support in the promotion and tenure process (a well-established faculty motivator).

Recognition. A supportive campus culture that includes formalized structures to recognize and reward community-based efforts significantly facilitates and legitimizes a department engagement initiative. At PSU, supportive promotion and tenure policies, annual awards, travel grants, and university communication vehicles actively encourage civic engagement efforts. In the mid1990s, PSU revised its promotion and tenure policies to expand the definition of scholarship and to recognize and reward the scholarship of engagement as well as other community-based activities (Portland State University, 1996). CAE hosts an annual campus-wide Civic Engagement Awards Ceremony where specific departments, community-based organizations, and individual faculty are formally recognized. The Office of Academic Affairs provides professional development travel grants; often, priority is given to individuals pursuing scholarly venues for their civic engagement activities. And monthly and quarterly university publications recognize and provide a regular dissemination venue for the scholarly civic engagement activities of faculty. These efforts contribute to high visibility and recognition of PSU's civic engagement efforts.

Promotion of mission and vision. PSU is an urban, public institution nationally recognized for its innovative curricular approaches and commitment to community engagement. The university motto, "Let Knowledge Serve the City," is well known and internalized by a majority of the faculty and student body; externally, the motto is also well recognized. This campus history and culture support a collaborative community-university environment $\longrightarrow$ one that facilitates the creation of, and regularly reinforces the operations of, the necessary central institutional structures mentioned earlier. Thus, where there is obvious community-focused alignment between department and university missions and vision such as at PSU, department and campus-wide engagement activities are more easily created and sustained. In institutional cases where the civic purposes of higher education are defined in less active terms or are deemphasized, encouraging department engagement initiatives would be significantly more challenging to support.

\section{An Integrated Model for Department Engagement}

Throughout this process, we have learned that an effective place to start with departments is to encourage the chair and supportive senior faculty to do an organizational scan of current activities. Departments can then develop a 
picture of their current and recent scholarly work, with a particular focus on community-based activities. This can be accomplished in a variety of ways over the course of a couple of months and then brought to the attention of the full department faculty during one or two unit meetings. We have found that faculty appreciate this activity; indeed, in many cases, it energizes them. A starting place might be to identify all the courses taught by department faculty, highlighting those that are required for the major and for various minors supported by the unit. Simultaneously, unit faculty could be invited to provide a list of all publications that are works in progress or that they have completed in the last three years. Finally, a list of the community partners (very broadly defined) that faculty are working with could be initiated. These partners may include private enterprises, not-for-profit organizations, and neighborhood, political, student, and other advocacy groups both on and off campus. The simple gathering of this information can be quite illuminating for everyone involved. It is very important to keep a broad definition of community engagement. Inviting faculty to share their accomplishments and works in progress with colleagues and aggregating the data in a low-tech, transparent manner can be very energizing for most, if not all, members of the department.

Next, any one of several things may take place, depending on the climate and context of the department. Some units have intentionally chosen short articles to read and discuss together-focusing on core disciplinary values or on the integration of civic learning into core curricula, for example. Other units have chosen to revisit their department mission or, in some cases, to rewrite it completely. Many advanced departments have found it useful to reanalyze their overall curriculum to identify where (in which specific courses, for example) key civic or other applied learning outcomes emerge. Once collective thinking amid the faculty takes place, a developmental approach to student learning within the major can emerge and, in many cases, erstwhile individualistic faculty orientations can give way to a sense of collectivity. Where the community is involved, commitments by one faculty member to a key community partner may transform into a deep department commitment. Over the course of years within the major, students from a variety of classes may engage in community placements that connect to and build upon each other. Relationships between faculty, students, and community members become durable, learning can deepen, and applied disciplinary research can have greater impact. Figure 11.1 shows one way to delineate some of the relationships in an engaged department. 
Figure 11.1

Model of Some of the Relationships in an Engaged Department

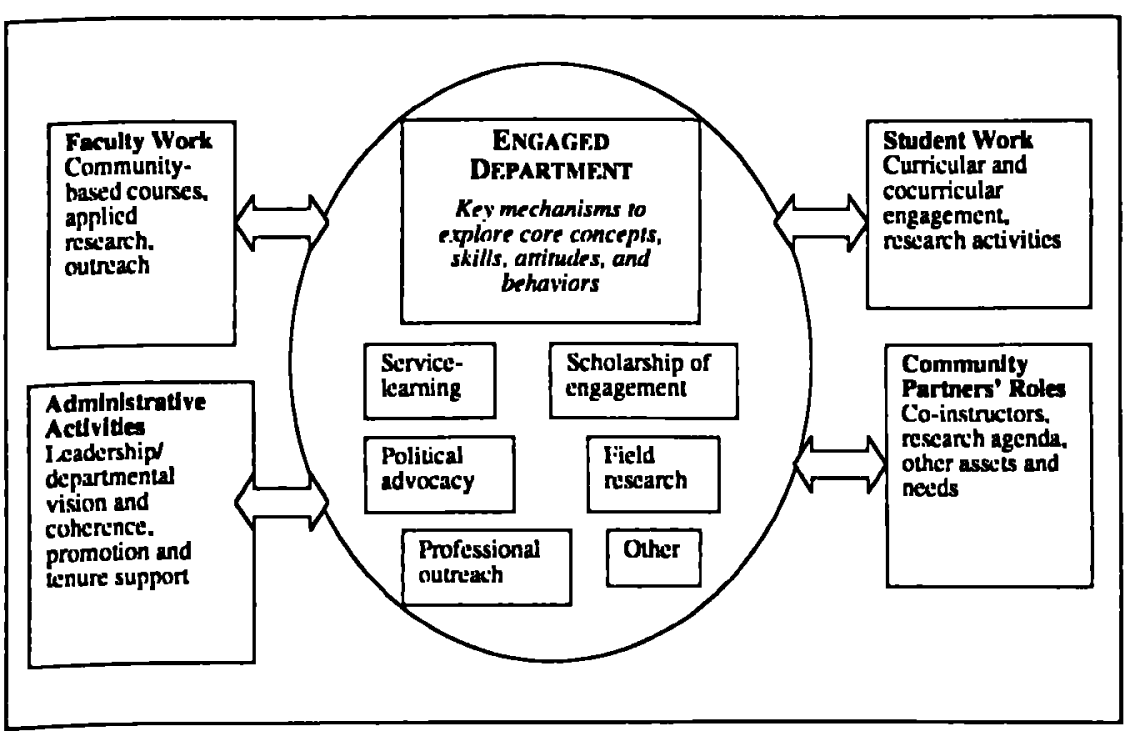

\section{Conclusions and Recommendations}

This experience and analysis leads us to four primary recommendations that supplement the many observations contained throughout this chapter.

- The role of leadership at all administrative levels is essential in supporting and fostering work on civic engagement. In a department initiative, the chair or director is a vital player in assisting faculty to begin this work and in providing validation to other faculty members of the centrality of this work to the department mission. Deans, provosts, and presidents all play additional roles in promoting civic engagement. Their specific roles are beyond the scope of this chapter, but their presence and support in reinforcing work at the department level is an important accelerator toward becoming an engaged institution.

- Relevance is key to success with respect to department engagement activities. Department conversations and discussion around core department mission(s) can be a way to (re)invigorate and (re)connect faculty to the core meaning and purpose(s) of their work. Seeking linkages to civic engagement is the next step if work such as that described here is to be 
accomplished in order to identify those relevant connections of department missions to teaching, scholarship, and service. An important part of efforts to create department relevance is to find definitions and frameworks that are relevant to the department's own work-terminology, inventories, assessment tools, expected student learning outcomes and competencies, relevant scholarship. These discipline-specific materials will greatly foster the department's ability to make civic engagement its own work.

- The organizational structure and process of an engaged department initiative is essential for a multi-department initiative to succeed. The initiative can best be organized by presenting it as a continuum from selfassessment (planning and initial status), through development, implementation, rewards, further assessment, and dissemination. The work of engagement is not an isolated, time-limited activity. When a central office facilitates the process, it is essential that there be sufficient staff and resources to support the initiative. Staff time is vital for organization, facilitation, and consultation. Resources are needed to provide key relevant documentation to each team, as well as whatever fiscal support is feasible for graduate assistants, travel, or other professional development needed to pursue engagement efforts. The development of Campus Compact's Engaged Department Toolkit (Battistoni et al., 2003) will greatly help institutions to conduct their own yearlong initiatives.

- Clarity of expectations for learning and accountability must be stated at the beginning so that departments know what they can expect of themselves and so that they understand what the institution expects them to do (and hopes they will accomplish). This might include steps we have described here, such as preparation of an initial self-assessment planning document, participation in learning sessions, use of consultation, and preparation of a final report/poster for dissemination. Teams need clarity from the beginning of the performance expectations so that they can plan appropriately - both to generate sufficient support within their own departments and so that they can have dedicated time to participate in a learning community with others from the institution.

The department (or equivalent academic unit) is a key organizational structure within higher education institutions and can be viewed as an important leverage point for developing and accelerating civic engagement efforts, as illustrated by the work described in this chapter. 


\section{Acknowledgments}

We gratefully acknowledge the fiscal support of the Corporation for National and Community Service and Portland State University. We also are indebted to the PSU participants in the Engaged Department Initiative, including: Department of English, Department of Mathematical Sciences, Department of Psychology, School of Business (management grouping), School of Community Health, School of Urban Studies and Planning (community development grouping), and University Studies (freshman inquiry grouping).

\section{References}

Battistoni, R., Gelmon, S. B., Saltmarsh, J., Wergin, J., \& Zlotkowski, E. (2003). The engaged department toolkit. Providence, RI: Campus Compact.

Campus Compact. (2001). Planning document for the engaged department institute. Providence, RI: Author.

Campus Compact. (2002). Intermediate institutes on the engaged department. Providence, RI: Author.

Leaming, D. R. (1998). Academic leadership: A practical guide to chairing the department. Bolton, MA: Anker.

Portland State University. (1996). Policies and procedures for the evaluation of faculty for tenure, promotion, and merit increase. Retrieved May 17, 2005, from www.oaa.pdx.edu/documents/pt.doc 